\section{Aboriginal study prompts push for action on children's hearing loss}

Melissa Sweet Sydney

The Australian government has been urged by the authors of a new study to make a topical antibiotic treatment available to Aboriginal children to help reduce the impact of an ear infection linked to hearing loss and educational difficulties.

A randomised controlled trial conducted by the National Aboriginal Community Controlled Health Organisation found that Aboriginal children with chronic suppurative otitis media were more likely to be cured if treated with ciprofloxacin drops than with the conventional treatment of topical framycetin, gramicidin, and dexamethasone (Medical Journal of Australia 2003;179:185-90.)
Among the 111 Aboriginal children who completed the trial, 52\% of those given conventional treatment were cured, compared with $76 \%$ of those given ciprofloxacin. Ciprofloxacin, however, is not currently registered for ototopical use in Australia.

Up to a quarter of children in some Aboriginal communities have evidence of perforated tympanic membranes, as a result of chronic suppurative otitis media, often described as a disease of poverty.

The World Health Organization says that when rates of the condition are above 4\% it indicates a massive health problem requiring urgent attention. Aboriginal children's poor access to prevention, treatment, and rehabilitation strategies was set out in a report published in June by the National Aboriginal Community Controlled Health Organisation, in which the organisation stated that $7 \%$ of Aboriginal children under age 15 have a hearing loss. In some of these cases, the loss was due to chronic suppurative otitis media.
Dr Sophie Couzos, a public health officer with the organisation, says that the findings of the new study have medicolegal implications. She said that previous research suggested that the conventional treatment, which is not recommended by the manufacturer for ototopical use, can harm the ear.

But policy makers are also under pressure from groups concerned about antibiotic resis tance to restrict the topical use of fluoroquinolones.

Dr Peter Collignon, an infectious diseases specialist in Canberra, said that antibiotic treatment is only one part of what should be a multifaceted approach to chronic suppurative otitis media, and that relying only on antibiotic treatment was a "short term band aid."

The National Aboriginal Community Controlled Health Organisation says that the study is a milestone, not only because of its challenge to standard practice but because of its pioneering research process. It was designed, developed, and implemented by Aboriginal Commu- nity Controlled Health Services under the slogan, "we are not jus participants, we are in charge".

The extensive community consultation meant that the study took far longer than originally envisaged, and recruitment was stopped early when funding from the National Health and Medical Research Council ran out.

Many Aboriginal communities are suspicious of research, feeling that it has often been focused more on researchers' needs than theirs. The council has recently consulted extensively with the Aboriginal communities with a view to making research more relevant to their health needs.

The researchers had permission from the Medical Journal of Australia to report their results back to participating communities before publication.

"There is an unrealised potential for Aboriginal Community Controlled Health Services to undertake large scale, community controlled research and to realise solutions to Aboriginal health problems," Dr Couzos said.

\title{
UN policy fails to tackle health needs of indigenous people
}

Upasana Tayal BMJ

Indigenous people worldwide are unable to access routine health care and are dying prematurely, despite efforts by the United Nations in the past decade to raise awareness.

This is a finding of a report published jointly by Health Unlimited (a British non-governmental organisation helping poor people achieve better health) and the London School of Hygiene and Tropical Medicine.

In 1995 the United Nations launched the international decade of the world's indigenous people, aimed at increasing international cooperation to tackle human rights, environmental, educational, and health problems these people face.

But the report, for which the researchers collected the health views and concerns of indigenous people from Namibia, Guatemala, Burma, Laos, and Cambodia, says that financial, geographic, and cultural barri- ers are still limiting access to basic Western health care and that Western medicines are deemed too expensive.

A 19 year old mother from Laos describes her experience: "My husband went to the district hospital for a consultation and treatment for high blood sugar, but only once because we couldn't afford 40000 kip (£3.50; \$5.50; €5) for a packet of tablets."

Where services are available, indigenous people are reluctant to use them because staff can be insensitive, discriminatory, and unfriendly, it says. "We didn't think about taking my son to a doctor because the truth is the health centre doesn't treat people well. They mistreat people," said a Guatemalan elder.

Utz' Wach'il: Health and Well Being Among Indigenous Peoples is at www.healthunlimited.org/aboutus/ indigenous $\% 20$ peoples.htm

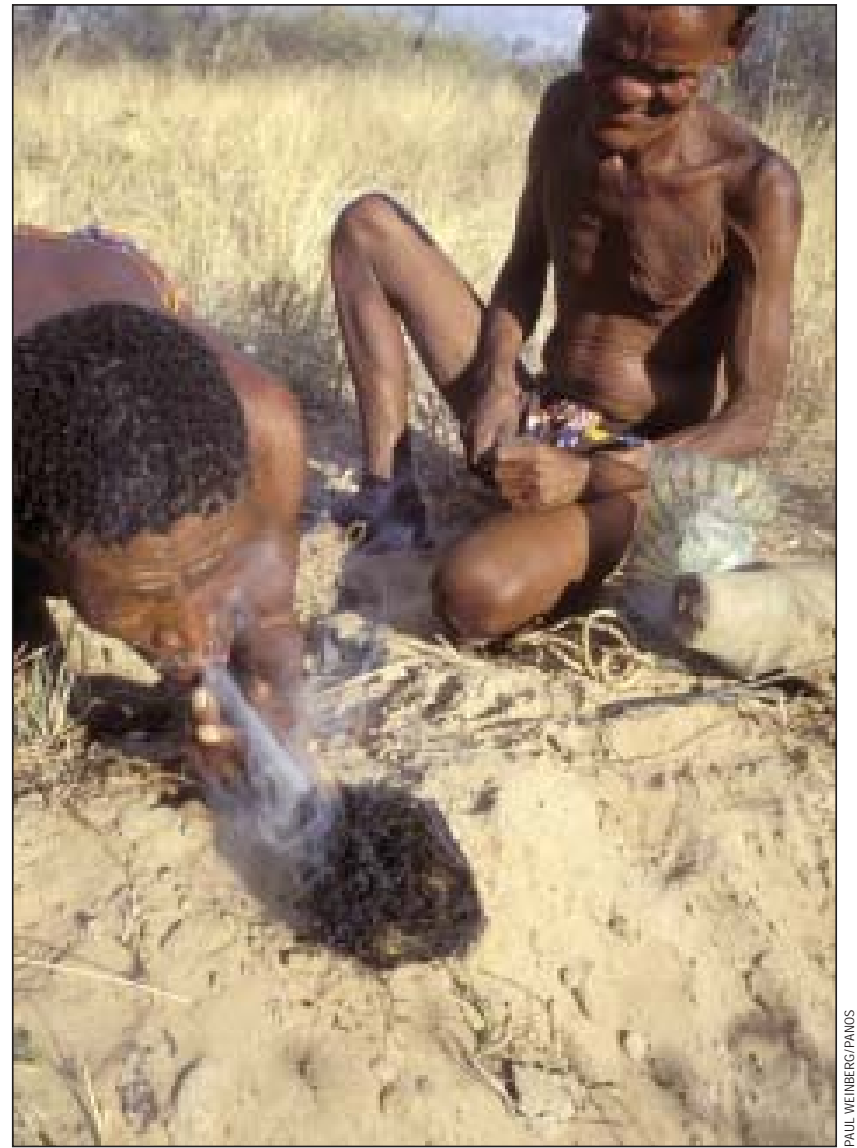

San bushmen making fire in Namibia 